\title{
Os estudantes do arquivo morto
}

Luciana Vigil Ferrão*

Décio Auler**

\section{Resumo}

Neste trabalho buscou-se compreender as causas da evasão escolar, bem como identificar possíveis redimensionamentos que contribuam para enfrentar esse problema. Em termos de encaminhamento teórico-metodológico, configurou-se como um estudo de caso, focalizando a evasão numa escola da rede estadual de ensino/RS, utilizando, como instrumentos de registro das informações, um questionário e uma entrevista semi-estruturada. Dentre os referenciais balizadores da pesquisa, destacam-se Harry Braverman e Paulo Freire. Os sujeitos da pesquisa foram estudantes que evadiram dessa escola e que não mais retornaram, sendo seus nomes localizados no denominado arquivo morto. $\mathrm{Na}$ análise dos resultados, optou-se pela análise de conteúdo. Os resultados foram sintetizados em três categorias temáticas: 1) cumprir programas, 2) interesse: fazer sentido estar na escola e 3) Currículo naturalizado. Estes resultados sinalizam a necessidade de, para superar a evasão da escola, problematizar e superar a lógica de organização do espaço-tempo dessa escola, inspirada na linha de montagem das fábricas do início do século XX.

Palavras-chave: Evasão escolar, espaço-tempo escolar, currículo e Ensino Médio.

\section{The dead file students}

\section{Abstract}

The causes of school evasion have been sought, as well as the identification of possible remolds which can contribute to face this problem. In terms of theoretical methodological direction, this research is designed as a case study, focusing the evasion in the Public Teaching/RS, and it has used a questionnaire and a semi-structured interview as tools of information register. Among the references who have initiated the research, there are Braverman and Paulo Freire as outstanding ones. The subjects of the research were students who evaded from this school and who have not returned anymore, having their names found in the referred dead file. In the outcomes' analyses it was chosen the content analyses. The results were synthesized into three thematic categories: 1) To fulfill programs, 2) Interest: to make sense being at school and 3) Naturalized syllabus. These

\footnotetext{
* Professora da rede estadual de ensino, Santa Maria, Rio Grande do Sul, Brasil.

** Professor Doutor da Universidade Federal de Santa Maria, Santa Maria, Rio Grande do Sul, Brasil.
} 


\section{Luciana Vigil Ferrão - Décio Auler}

results point out the necessity of, in order to overcome the school evasion, problematize and overcome the logic of organization of school space-time, inspired in the factories' assembly line in the beginning of $20^{\text {th }}$ century.

Keywords: School evasion, School space-time, Syllabus and high-school.

\section{Considerações iniciais}

Esse artigo sintetiza resultados de pesquisa que buscou compreender as causas da evasão escolar, bem como sinalizar redimensionamentos que contribuam para enfrentar a situação. Apoiou-se em referenciais que problematizam discursos, transformados em senso comum pedagógico, cuja tônica é a culpabilização do indivíduo pelo fracasso na escola, mediante a utilização de expressões como "aluno preguiçoso", "vagabundo", "não quer nada com nada", "não ficam quietos como antigamente" e "a família não impõe limites".

A motivação para a pesquisa esteve relacionada ao fato de uma autora do artigo atuar profissionalmente em uma escola da rede estadual de Educação Básica, do Rio Grande do Sul, local da pesquisa, vivenciando, cotidianamente, o problema da evasão. Nesse sentido, o problema de pesquisa consistiu no aprofundamento da compreensão sobre a questão: quais as causas da evasão escolar, em escola da rede estadual de Educação Básica do Rio Grande do Sul? Nesta pesquisa, buscou-se dar voz a sujeitos que evadiram e não mais retornaram à escola. Na localização desses sujeitos, deparou-se com o denominado arquivo morto. ${ }^{1}$ Tal denominação constitui o local onde são guardados arquivos não utilizados sistematicamente, como informações sobre os estudantes que saíram da escola sem terem retornado.

No que tange ao encaminhamento teórico-metodológico, a pesquisa esteve alicerçada em Braverman (1987) e Freire (1985, 1987 e 1992). Utilizouse, como instrumentos, um questionário, complementado por uma entrevista semi-estruturada, a qual teve como finalidade aprofundar a compreensão sobre as causas da evasão. $\mathrm{Na}$ análise dos resultados, utilizou-se a análise de conteúdo proposta por Bardin (1977). Estes foram sistematizados em três categorias temáticas: 1) cumprir programas; 2 ) interesse: fazer sentido estar na escola e 3) currículo naturalizado.

\section{Currículo: organização do espaço-tempo na escola}

Há muitos estudantes que não estão ocupando o espaço da escola e muito menos ficando o tempo destinado para tal. Quais os significados contidos na construção desse espaço-tempo escolar para o estudante estar afastandose dele? A estruturação desse espaço-tempo foi inspirada na organização fabril. Segundo Faria Filho e Vidal (2000), ao findar o século XIX, era preciso que a educação escolar, na figura da escola, sobressaísse diante de outras institui- 
ções que realizavam a função de ensinar como a família e a igreja. Isso seria feito através da construção de prédios específicos para esse fim com o intuito de uma ação mais eficaz com as crianças. Semelhante a fábricas, a escola, já à época de seu surgimento, possui uma organização fragmentada a fim de atender um maior número de estudantes. E, desde então, conserva essa característica. Muitas das relações, na escola, ainda se caracterizam pelo modelo fordista/ taylorista.

Fordismo ${ }^{2}$ e taylorismo ${ }^{3}$ são formas de organização da produção no processo de expansão do capitalismo. Na análise de Braverman (1987), diferentemente de outras espécies de animais, movidas por atividades instintivas, sendo instinto e execução indivisíveis, nos humanos, a concepção e a execução de tarefas podem ser separadas, fragmentadas. A ideia de uma pessoa pode ser executada por outra. Tal possibilidade constitui a base da organização da produção capitalista. Uns poucos, os donos do capital, dos meios de produção, concebem a organização de tal produção enquanto os que vendem seu trabalho, os trabalhadores, meramente executam a ação concebida por aqueles. O filme Tempos Modernos, lançado em 1936 por Charles Chaplin, é ilustrador dessa dinâmica.

Ainda segundo Braverman (1987), a intensificação desse modelo de produção ocorre com o denominado fordismo/taylorismo, havendo a progressiva aceleração na execução das tarefas, nas linhas de montagem, com a gerência científica de Taylor, aumentando os ganhos do dono do capital. A separação entre concepção e execução, a fragmentação, assim como a aceleração cada vez maior das tarefas, vem acompanhada da degradação do trabalho e dos trabalhadores. Seu cérebro torna-se ocioso, a unidade entre cérebro e mãos (músculos) é rompida. É a fragmentação da unidade entre pensamento e ação, degradação do ser humano.

Porém, esta organização, que reuniu na fábrica um grande número de trabalhadores, segundo Braverman (1987), muitas vezes associada com prisões, reformatórios e orfanatos, não esteve imune a contestações. Surgem greves e uma grande evasão de trabalhadores. Foram revoltas contra a repetição mecânica e tediosa de tarefas nas linhas de montagem, contra a aceleração nos ritmos de realização das mesmas. Braverman (1987) cita análises, da época, que buscavam compreender o fenômeno, as quais destacam que "a indústria norte-americana, em alguns casos, pode ter impulsionado a tecnologia em excesso, fracionando as funções em partículas a tal ponto que atingiu o limite da resistência humana. [...] Devemos ter criado funções demasiado tolas para serem preenchidas por numerosos tolos" (p. 40).

O currículo, aqui entendido como organização espaço-temporal da escola, encontra, nessa organização fabril, nessa lógica, sua inspiração. A educação bancária, ainda em pleno vigor, denunciada por Paulo Freire (1987), herdou essa lógica. A base da organização da produção capitalista, na fábrica, ou 


\section{Luciana Vigil Ferrão - Décio Auler}

seja, a separação entre concepção e execução, constitui a lógica, a concepção que fundamenta o currículo escolar. Alguns poucos o concebem e muitos os professores, devem, tal qual Chaplin no filme Tempos Modernos, executá-lo. Cumprir programas vencer conteúdos são as principais tarefas dos professores. $\mathrm{Na}$ fábrica, tal organização tinha a intencionalidade de aumentar a extração de mais-valia. $\mathrm{Na}$ escola, os professores executam programas não isentos de intencionalidades. Por exemplo, um currículo pode estar voltado para o controle ou para a emancipação/autonomia. Nesse processo há, inclusive, uma fragmentação na atividade intelectual. Alguns, os técnicos, não neutros, a serviço de interesses/intencionalidades, concebem o currículo, como caminho a ser percorrido (SILVA, 2004). Outros, os professores, expropriados de conceber currículos, pensam, concebem alternativas metodológicas para cumprir esse currículo, para tornar a estrada o caminho proposto menos desagradável. Tentam dourar a pílula.

Cronômetros e relógios, como na fábrica, definem os tempos de permanência em determinados espaços. Por exemplo, 50 minutos na aula de educação física, 50 minutos na de filosofia, 100 minutos na de matemática, 100 minutos na de química e assim por diante. Máxima fragmentação das tarefas, repetição mecânica na linha de montagem. Máxima fragmentação curricular. Conhecimentos disciplinares sem sentido para o estudante, sem conexão com sua experiência de vida. É semelhante a um sapato, em processo de fabricação, na linha de montagem, que passa de mão em mão, cujo somatório de operações mínimas resulta no produto final o estudante passa de ano a ano, de professor a professor, os quais devem agregar-Ihe uma lista numerosa de conteúdos. Porém, diferentemente do sapato, o estudante pode recusar esses depósitos (educação bancária). Ele pode reagir, tornar-se "indisciplinado" ou ir embora.

Controle de turma, manter a disciplina, termos comuns em orientações a estagiários, futuros professores. Controle e disciplina, preocupação central de Taylor. Novamente recorrendo a Braverman (1987), em sua análise da organização fabril, citando documentos da época, o autor destaca que "era simplesmente para fins de disciplina, de modo que os trabalhadores pudessem ser eficazmente controlados sob a supervisão de um capataz. Sob um teto [...]" (p. 66).

\section{Evasão: fracasso ou exclusão?}

Fracasso ou exclusão. Não se trata, apenas, de nomenclaturas diferentes para designar o mesmo fenômeno. Expressam concepções e compreensões distintas sobre o mesmo problema: a evasão. Nesse trabalho, descarta-se a concepção de evasão como fracasso escolar. Não se endossa a culpabilização dos estudantes pela evasão. Conforme Del Pino (2009), a noção de fracasso escolar coloca o estudante como responsável único pela evasão, ignorando a responsabilidade de outros agentes, como condicionamentos sociais, sistema escolar, etc. Entende-se que a evasão escolar é afetada por múltiplos fatores. 
Em pesquisa realizada sobre o denominado fracasso escolar, sendo focalizadas teses e dissertações defendidas entre 1991 e 2001, foram encontradas e categorizadas 71 obras, das quais 13 foram analisadas em profundidade. Como síntese do estado da arte, o artigo destaca

\begin{abstract}
Revelaram-se vertentes que compreendem o fracasso escolar das seguintes formas: como problema essencialmente psíquico; como problema meramente técnico; como questão institucional; como questão fundamentalmente política. Verificou-se a existência de continuidades e rupturas teórico-metodológicas em relação aos caminhos percorridos pela produção de saber na área: há teses em que permanece o predomínio de concepções psicologizantes e tecnicistas de fracasso escolar; em outras, coexistem concepções inconciliáveis que resultam em um discurso fraturado; há também teses que dialogam e avançam a pesquisa crítica do fracasso escolar, inserindo-o nas relações de poder existentes numa sociedade de classes. (ANGELUCCI, et al. 2004, p. 51)
\end{abstract}

Em outras pesquisas realizadas sobre causas da evasão escolar (MIDEPLAN, 2008), constatam-se resultados interessantes. Quando essas são realizadas com professores, em suas justificativas sobre evasão escolar, predominam aspectos mais ligados ao campo sociológico, como por exemplo, falta de recursos econômicos da família, troca da escola pelo trabalho, atividades de casa, motivação e participação dos pais no processo educativo. Ou seja, fatores que podem ser considerados externos ao âmbito escolar. Por outro lado, em pesquisas (MIDEPLAN, 2008) nas quais os sujeitos participantes foram estudantes, predominam elementos mais vinculados ao campo pedagógico, como a estrutura interna da escola, seu currículo, etc. Parece que refletir sobre o que ocorre dentro da escola causa certo desconforto entre os docentes, sendo usual, em termos de mudanças, admitir-se, no máximo, o uso de novas metodologias, de novos recursos didáticos. Porém, passada a novidade inicial, volta-se, logo, ao mesmo desânimo. Desânimo tanto dos professores quanto dos estudantes.

Não estaria a evasão, acima de tudo, relacionada com o currículo? currículo entendido como caminho a ser seguido, como algo que vai muito além de um elenco de conteúdos disciplinares. O currículo concebido como o conjunto das experiências de aprendizagem, intencionais ou não, explícitas ou implícitas, decorrentes da organização do espaço-tempo da escola. Possivelmente esteja chegando o momento de se cogitar a necessidade de problematizar, profundamente, a organização desse espaço-tempo e as experiências de aprendizagem nele propostas. Talvez o abandono (evasão) esteja, acima de tudo, relacionado a não adaptação do jovem à padronização, ao controle imposto pela organização espaço-temporal da escola. Qual foi a postura de muitos trabalhadores que não se adaptaram à organização fabril, inspiradora da organização da 
escola? O abandono. Braverman resgata significativo número de relatos desse cenário. Por exemplo

Os homens da Ford começaram a abandoná-la em grande número em princípios de 1910. Com a chegada da linha de montagem suas seções ficaram literalmente desertas: [...] Tão grande era o desgosto do trabalho com as novas máquinas que, por fins de 1913, toda vez que a companhia precisa aumentar 100 homens à sua fábrica tinha que admitir 963. (BAVERMAN, 1987, p. 131-2).

Currículo, uma organização do espaço-tempo, em geral, sem significado para os estudantes. A escola, ainda hoje hegemônica, de alguma forma, imita essa fábrica capitalista. Por volta de 1970, as empresas automobilísticas acusavam altos índices de abandono diário e mensal em suas fábricas, havendo queda de produção. Segundo análise de Braverman (1987), isso estava relacionado ao descontentamento dos trabalhadores com a falta de sentido em suas atividades na fábrica. Além disso, os grandes índices de insatisfação, que predominavam entre os jovens trabalhadores, nos Estados Unidos, estavam principalmente ligados a funções repetitivas, monótonas e fragmentadas, dentre outras características que levaram a uma taxa de evasão anual de $30 \%$.

Além da separação entre concepção e execução do currículo, do espaço-tempo escolar, cabe não negligenciar que este constitui um espaço marcado por intencionalidades, definidas no âmbito de sua concepção. Determinadas dimensões da cultura, de determinada sociedade, são priorizadas em detrimento de outras. Essas valorizações desiguais, transformadas em currículo, geram resultados distintos para distintos grupos socioeconômicos, submetidos a um mesmo currículo. Assim, para os diferentes, para os desiguais, currículos iguais, pensamento liberal e conservador, o qual, assumido ingenuamente, faz sucumbir muitas propostas educacionais discursivamente transformadoras. Em síntese, um currículo comum a todos não será suficiente para favorecer igualdade. Ou seja, defende-se uma igualdade como ponto de chegada e não de partida, ressalvando que se postula a igualdade sempre que a desigualdade inferioriza.

\section{Encaminhamento teórico-metodológico}

Neste trabalho buscou-se investigar e discutir possíveis causas da evasão escolar, bem como sinalizar redimensionamentos que contribuam para enfrentar a situação. O problema de pesquisa consistiu em aprofundar a questão: quais as causas da evasão escolar em escola da rede estadual de Educação Básica do Rio Grande do Sul? Diferentemente da maioria das outras pesquisas, nesta os sujeitos envolvidos foram estudantes que evadiram e não mais retornaram. A investigação configurou-se como um estudo de caso, ou seja, a evasão na referida escola. 
Na localização destes sujeitos, seus nomes constavam no "arquivo morto", assim denominado por ser pouco ou não procurado. Este arquivo constitui o local onde ficam as informações sobre os estudantes que saíram da escola sem terem retornado. A pesquisa abarcou o período de 2005 a 2007, sendo que, em 2007, a instituição contava, no âmbito da Educação Básica, com 1.025 estudantes e 78 professores. Esta é credenciada no Programa Especial de Ingresso ao Ensino Superior (PEIES), desde 1995, seguindo a "listagem de conteúdos" sugerida, para cada um dos três anos do Ensino Médio, com avaliações anuais pela Universidade Federal de Santa Maria/RS.

Entre os estudantes evadidos, chamou a atenção o alto índice de evasão, no primeiro ano do Ensino Médio, em relação ao total de evadidos. Assim, dentre estes selecionou-se os sujeitos da pesquisa. Nesta situação, encontrou-se, no arquivo morto, o nome de 188 estudantes. Cada um desses nomes foi submetido ao sistema de informática da escola, constatando-se que 91 estudantes já haviam concluído o Ensino Médio ou estavam matriculados em outro curso da própria escola, ou transferidos. Logo, ficaram 97 estudantes. Destes, 13 nomes apareciam repetidos na lista, ou seja, evadiram no mínimo duas vezes durante o período pesquisado. Assim, resultaram 84 estudantes pré-selecionados para a investigação.

Deste conjunto, 24 responderam ao primeiro instrumento de pesquisa, um questionário (Apêndice 1). O contato com os outros 60 estudantes ficou comprometido por várias razões: não encontrados no endereço indicado, mudança para outra cidade, conclusão do Ensino Médio (mediante provas da Secretaria Estadual de Educação) e não devolução do questionário.

Além do questionário, o qual teve a função de um primeiro levantamento sobre a situação atual do estudante evadido, bem como sobre as causas da evasão, utilizou-se uma entrevista semi-estruturada (Apêndice 2), conforme Triviños (2008), com a finalidade de aprofundar a compreensão sobre as causas da evasão.

O critério para a escolha dos estudantes para a realização da entrevista semi-estruturada, a partir das respostas dadas ao questionário, foi a atribuição a fatores intra-escolares, ou seja, situados no campo pedagógico, a causa da evasão. Por exemplo: "Eram muito difíceis as matérias que eram passadas" (E4), " "Períodos muito longos" (E5), "Por motivo de desinteresse, não via futuro nos estudos" (E7), "O que tinha fora da escola me chamava atenção... ou devia ter alguma coisa lá dentro da escola que não me chamava a atenção" (E8). Dessa forma, selecionaram oito estudantes para a entrevista. 


\section{Luciana Vigil Ferrão - Décio Auler}

\section{Análise dos resultados}

$\mathrm{Na}$ análise dos resultados, utilizou-se a análise de conteúdo proposta por Bardin (1977). Neste processo, as falas dos estudantes dialogam, principalmente, com Braverman e Freire, citados ao longo deste trabalho. Braverman comparece com elementos que contribuem para compreender a organização do espaço-tempo dessa escola e Freire com a sinalização de um novo currículo, currículo pensado a partir da experiência de vida dos estudantes, com categorias como curiosidade epistemológica e educação problematizadora e dialógica. Os resultados foram sistematizados em três categorias temáticas: 1) cumprir programas, 2) interesse fazer sentido estar na escola e 3) naturalização do currículo. A análise de cada uma dessas categorias inicia com um desenho de Frato, pseudônimo de Francesco Tonucci (2008), pesquisador e desenhista italiano que dá voz às crianças e satiriza a escola.

\section{Cumprir programas}

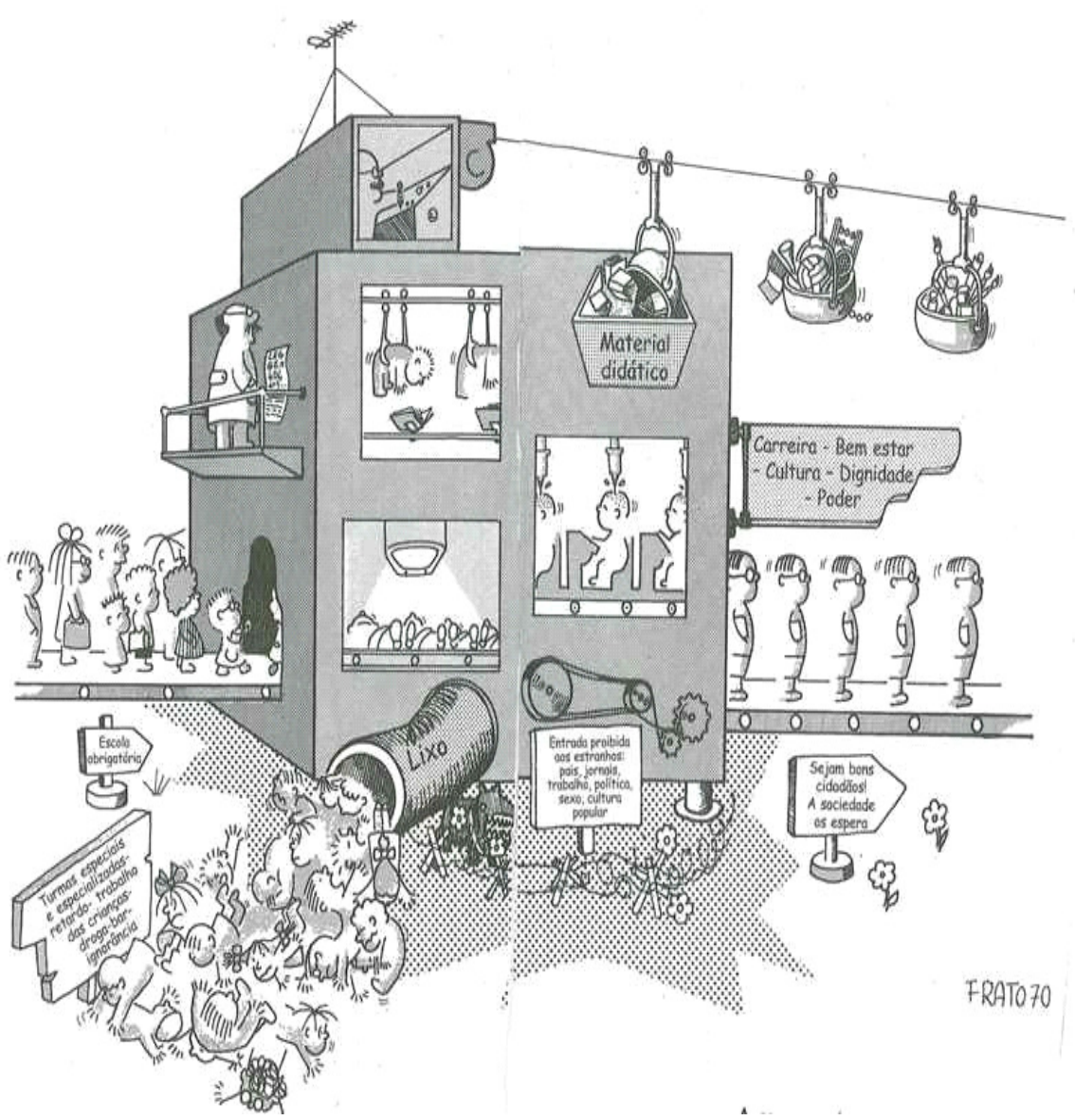


Esta categoria focaliza uma das dimensões relacionada à evasão: a rapidez com que os conteúdos são trabalhados. Os estudantes revelaram impotência e, por vezes, revolta em não conseguir acompanhar a pressa dos professores em "vencer os conteúdos". Possivelmente este ritmo acelerado esteja associado à suposta necessidade de cumprir programas, de vencer conteúdos, transformando, dessa forma, estudantes e professores em executores do que é concebido longe da escola (cabe não negligenciar o fato de que esta escola está cadastrada no PEIES, assumindo uma programação externa), para um estudante idealizado, não considerando os sujeitos reais da escola. Aumentase a velocidade com que é "passado" o conteúdo, independente da efetiva aprendizagem, pois mais conteúdo pode ser vencido ou executado, executado porque esse foi selecionado fora da escola (como o material didático que chega de fora, no desenho de Tonucci, citado anteriormente).

Segundo sujeitos da pesquisa,

Eu procurava me interessar, eu procurava pegar a matéria, só que não adiantava, eu não conseguia, ele explicava muito rápido $[. .].(\mathrm{E} 1)$.

E passavam no quadro e em seguida já apagavam. A gente recém tava copiando, nossa, era bem rápido mesmo. Daí não dava tempo [...]. Aí a gente nem entendia aquele assunto eles já iam pra outro, pra outra coisa e [...]. Nada a vê. (E4).

Para Braverman (1987), citando relato sobre greve ocorrida em 1972, em fábrica da General Motors,

O principal problema em discussão na greve era o aumento de ritmo das operações no mês de outubro anterior (1987, p. 39).

Na escola, o professor não detém a unidade do processo, é responsável apenas por uma parte do todo: vencer os conteúdos. Poucos estudantes acompanham essa rapidez. Rapidez que abandona a maioria, deixando-os para trás, rotulando-os de fracassados. É a culpabilização do indivíduo, associada à desconsideração da diversidade e dos condicionantes sociais.

Os pressupostos freireanos, sinalizando horizontes que apontam para além do "vencer conteúdos, assumidos nesta pesquisa, remetem a um profundo repensar do papel do professor, da comunidade escolar. Professor, estudante e comunidade escolar passam a ser protagonistas no processo de pensar currículos e não meros executores. Currículos estruturados de e para sujeitos reais, sendo sua experiência de vida o ponto de partida. 
Interesse: fazer sentido estar na escola.

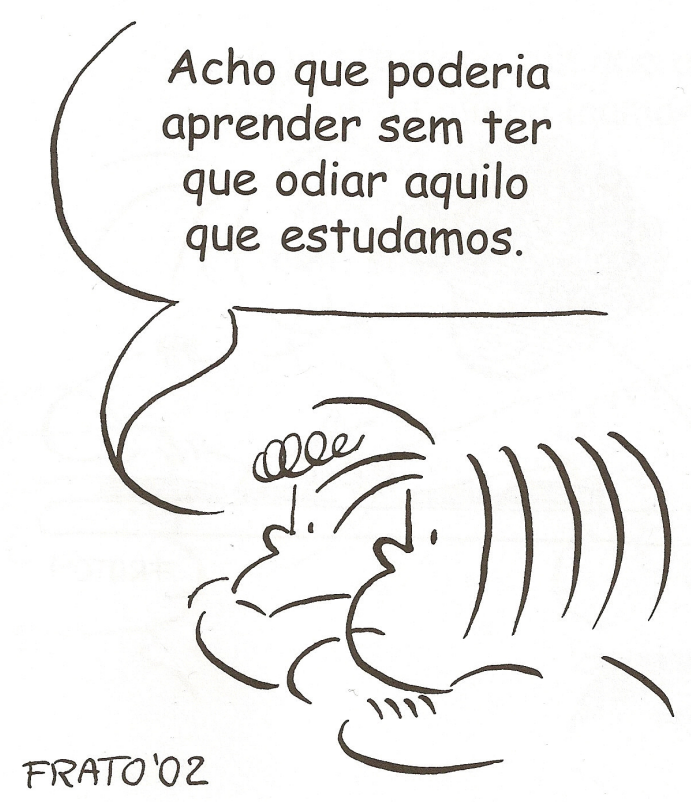

Esta categoria analisa uma possível relação entre o desinteresse, a falta de significado do que se faz na escola e a evasão escolar. Essa falta de interesse está relacionada, segundo compreensões dos estudantes, as muitas fórmulas, cálculos, textos, muitos dos quais sem sentido e que levam o estudante a "dispersar na aula". Cumprem-se programas com os quais o estudante não identifica ressonância com o seu mundo, com sua vida fora da escola. A organização do espaço-tempo escolar constitui-se num mundo estranho, estranho ao mundo da vida. Ao mesmo tempo em que analisam criticamente o currículo desta escola, há sinalizações, por parte de estudantes, que apontam para a superação do sem sentido em que se transformou a escola,

Uma coisa que te chame atenção, mas agora, agora vou, vou ter essa aula nojenta, mas depois vai ter uma coisa pra todo mundo. Uma, ou uma matéria que, enfim, uma coisa que se trate de, não só de, de, de cálculo, de letra de? Uma coisa que se trate de, de mundo, de pessoas, né? Isso é muito bom, eu acho que chama a atenção isso aí... Se tratar o mundo lá dentro, entendeu? Se tratar o assunto lá dentro [...]. Pra mim o x da evasão é se o assunto envolver, tu sai da escola falando do assunto, talvez isso não resolva o problema, mas vai fazer o aluno pensar. Eu não lembro de ter saído depois do portão da 
escola discutindo: ah, como é que tu resolveste aquele problema de matemática? (E8).

É só esse o ponto. O ponto que, que eu mais me refiro é esse aí ó. Não existiria isso, a preguiça [...]. Se tivesse alguma coisa que chamasse atenção lá dentro, tivesse alguma coisa que chamasse atenção lá. (E8).

Uma análise de Sacristán (2000) ajuda a compreender, bem como sinalizar encaminhamentos para a manifestação presente na charge de Frato ("Acho que poderia aprender sem ter que odiar aquilo que estudamos"), assim como a manifestação do estudante E8. Para esse autor, o fracasso escolar, a desmotivação dos alunos, dentre outros aspectos, têm relação com o currículo, e sintetiza destacando:

Quando os interesses dos alunos não encontram algum reflexo na cultura escolar, se mostram refratários a esta sob múltiplas reações possíveis: recusa, confronto, desmotivação, fuga, etc. (SACRISTÁN, 2000, p. 30)

Relembrando a organização do espaço-tempo, na escola itinerante, ${ }^{5}$ frequentada pelo entrevistado sete, antes da escola atual, da qual evadiu, relata uma outra organização, na qual as pessoas, a vida, os problemas vividos eram trabalhados estudados:

Aqui é só aula, aula, aula, aula e aprender e é isso e deu. Lá pra fora tu aprende tudo, tudo, tudo, tudo. Não tem como não [...] Até nós tinhamos uma equipe pra recepcionar pessoas quando chegavam lá, mesmo sendo nossos pais que tavam entrando dentro do colégio. Chegava: "bom-dia", oferecia café, uma coisa, levava pra sala, ou ia conversar com os professores, uma coisa assim (E7).

Durante a entrevista do oitavo sujeito (E8), sua mãe adentra na discussão, estabelecendo-se um diálogo de uma profundidade muitas vezes não alcançada, por profissionais da educação. No que tange a evasão, para a mãe, a solução estaria no campo da psicologia, devendo ser contratados psicólogos que, mediante o diálogo com os estudantes, reduziriam a evasão. O filho (E8) discorda e explica para sua mãe que, se o estudante não quer estudar, não tem interesse, não irá estudar. E ainda, mesmo tendo psicólogos na escola ou outro profissional para conversar, o que fará o estudante ficar na escola é esta tratar do que é significativo, o que é de seu interesse,

Mas assim mãe [...]. Tem aluno que não quer. Mesmo se for na [...]. Tendo psicóloga que seja na escola [...]. Ou tendo isso, ou tendo aquilo [...]. Tem que ser uma coisa 


\section{Luciana Vigil Ferrão - Décio Auler}

que agrade ele, que ele estude, mas que agrade ele também, entendeu? [...]. Mas aquele lado que agrade ele tá ajudando ele a estudar o português e a matemática que eu me refiro, que é as matéria, que é o dia a dia da escola, entendeu? (E8).

- Motivação? (Mãe)

- Motivação. (E8)

Na fábrica, algo semelhante: [encontram-se semelhanças]

Os gerentes informam com estarrecimento que alguns operários da linha de montagem são de tal forma desinteressados a ponto de irem-se embora em pleno expediente, sem mesmo voltar para receber pelo tempo que trabalharam. (BRAVERMAN, 1987, p. 38)

Sinalizando outra dinâmica para a escola, na qual a vida adentra, sendo objeto de estudo, o oitavo entrevistado destaca uma possível postura do professor(a):

[...] "Ah o que vocês acharam do quilômetro de arrancada lá?" Os guri gostam de carro e tal. Todo mundo se interessa. "Ah vão se interessar aqui? Então, vamos fazer um cálculo aqui pra vocês, de física, aqui e tal". Não tô dizendo que tenha que ser assim, mas eu acho que, no meu ponto de vista, é que possa ser (E8).

Motivação e interesse são dimensões, segundo Freire e Shor (1986), estritamente vinculadas ao currículo. Para Freire (1992), o querer conhecer antecede o conhecer. Pensar currículos a partir do que denomina de saberes de experiência feitos aguça esse querer conhecer, a curiosidade epistemológica. Freire (1985) destaca também que o atual ensino pode ser caracterizado pela busca incessante em dar respostas a perguntas não feitas. Essa educação da resposta em nada contribui para a curiosidade indispensável para o processo cognitivo. 


\section{Currículo naturalizado}
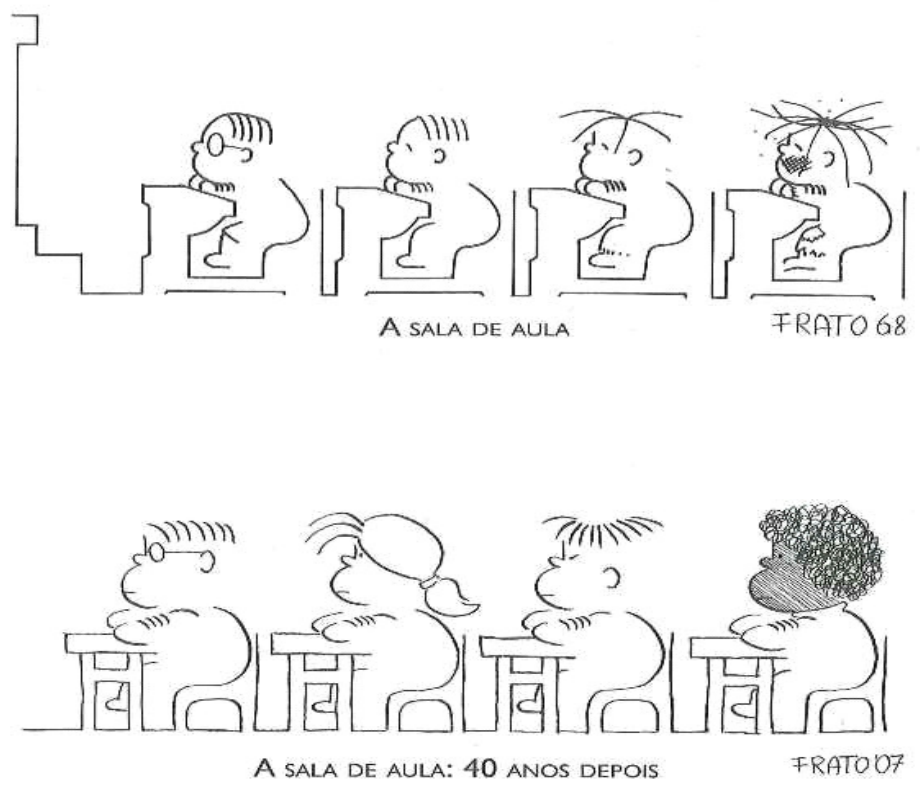

Além das dimensões anteriores, outra causa para o abandono, conforme os estudantes evadidos, é a rotina da escola. A perspectiva de voltar à escola, depois de evadir, de acordo com os sujeitos do arquivo morto, é desestimulante. Mesmo após terem ficado algum tempo fora da escola, quando voltam, reencontram sempre a mesma coisa.

Aí tá louco, eu fiquei muito desesperada por que eu não consegui passar. Daí eu voltar e fazer tudo de novo, do mesmo jeito. Tinha matérias que mudava um pouquinho, mas só um pouquinho, mas no geral era tudo igualzinho de novo. Isso cansa, pensa que tu vai voltar lá pra vê o que tu já viu e do mesmo jeito ainda. Dá um desânimo. (E3).

É por que aquele português, aquela matemática, aquela física, aquela química é que [...] a de sempre entendeu? Não tem aquela outra, não tem uma outra [...]. Aquela coisa que te chame atenção [...]. É, voltei noutro ano e tinha a mesma coisa. (E8).

Porém, apesar da rotina, da repetição que causa desinteresse, a maioria dos estudantes entrevistados assume esta escola como a única possível. Esta categoria também se relaciona com a internalização, a naturalização do currículo, considerando-o como dado, destituído de historicidade por parte 


\title{
Luciana Vigil Ferrão - Décio Auler
}

dos estudantes. Isso é percebido, por exemplo, quando receiam em questionálo. É com espanto que reagem perante a problematização, na entrevista, de possíveis mudanças nesta estrutura. Esta escola é desestimulante, mas inquestionável. É assim que a maioria dos estudantes desta pesquisa concebem-na. Currículo naturalizado, passividade internalizada.

Mas é uma matéria, uma matéria que tem no colégio a gente tem que estudar, né? (E6)

Ao serem questionados sobre possíveis mudanças de disciplinas no programa da escola, os sujeitos da pesquisa não concebem essa possibilidade, pois, segundo eles, se a escola determinou, é por que deve ser assim. Mesmo que esse currículo não faça sentido.

Exceto o entrevistado oito, os demais evidenciam conformação com a rotina da escola. Acatam essa rotina, a repetição, sem vislumbrar outra possibilidade, outra escola. Há uma tendência, dentre os sujeitos da pesquisa, em não questionar, ao menos explicitamente, esta escola. Mas em abandoná-la. Contrariamente,

Como eu te falei, alguma coisa do que todos participem, todos gostem... Mudar, tirar a rotina da escola. Terminar com a rotina por que quando cai na rotina, caiu na rotina, né? Aí, estraga tudo. (E8)

A discussão desta categoria, ilustrada com a charge de Frato, na qual, após 40 anos, a organização espaço-temporal da escola sofreu poucas modificações, pode ser aprofundada com a análise que Sacristán (2000) faz sobre o que denomina de "Cultura Escolar" e "Currículo Exterior" à escola. Segundo ele,

\begin{abstract}
Hoje, o cidadão médio certamente tem mais informação sobre o universo, a ciência e a tecnologia, as culturas de outros povos, a literatura, a música, os idiomas, etc., graças às revistas de divulgação científica, aos fascículos, aos meios de comunicação, às visitas a museus, às experiências e educação extraescolares, às viagens, etc., do que pelas aprendizagens escolares. (SACRISTÁN, 2000, p. 71)
\end{abstract}

Este autor destaca que as aprendizagens propostas, no currículo escolar, mantêm-se muito dissociadas da aprendizagem experiencial extraescolar dos estudantes. Tal dissociação está deixando o currículo escolar cada vez mais obsoleto. Como reação dos estudantes, o abandono, a desmotivação, o fracasso e outras formas de resistências e rebeldias contra a instituição escola, a qual, por apresentar-se cada vez mais obsoleta, tenta impor-se mediante recursos disciplinares, acentuando, cada vez mais, procedimentos repressivos. 
Contudo, Sacristán alerta:

Os canais extraescolares são atrativos, sem dúvida, e necessários, mas é preciso ver quando servem para liberar os indivíduos e lhes dar consciência crítica e quando são elementos de alienação e consumo. (2000, p. 71)

\section{Considerações}

Na fábrica, para suportar o tédio das funções repetitivas, existia o pagamento. Na escola, tal qual numa transação bancária, o pagamento pela execução de tarefas feitas, em geral sem sentido, é feito através das notas, resultantes, muitas vezes, de médias aritméticas ponderadas. Dinheiro e nota, motivações usadas na fábrica e na escola para suportar o insuportável: a perda de sentido da ação humana. Para Taylor, fundamental para o controle, para a disciplina, para concentrar as decisões em poucas pessoas, expropriar do trabalhador seu conhecimento (BRAVERMAN, 1987) ligado aos seus antigos ofícios. Na escola, na concepção bancária, ainda hegemônica, é ignorar a experiência de vida, o conhecimento que o estudante traz para a escola. Na gerência científica de Taylor, são decisões externas sobre o tempo que cada trabalhador terá para executar determinada tarefa. Na escola, o professor decide, em seus planejamentos, o tempo necessário para desenvolver cada conteúdo, tal qual a tarefa na fábrica. E o estudante? Este é uma abstração, um ser idealizado. Supostamente, todos levam o mesmo tempo para "aprender" determinado conteúdo. Um planejamento centrado no currículo a ser cumprido, não no estudante, na sua experiência de vida. Tal qual o trabalhador, excluído de qualquer participação em tomadas de decisão. Este é o espaço-tempo escolar que forma (formata) o sujeito, quase objeto, controlável. E, nessa lógica, ainda se fala em preparação para a democracia, para a cidadania. Felizmente o estudante reage. Porém, raramente se buscam as causas de suas reações. Já identificada em trabalho anterior (AULER, 2007), os resultados desta pesquisa robustecem a convicção de que há uma lacuna, um vácuo no processo educacional. Lacuna associada ao querer conhecer, o que Paulo Freire (1992) denomina de curiosidade epistemológica. Ou Charlot (2009), de estar mobilizado intelectualmente. Em Freire, o querer conhecer antecede o conhecer. Para este educador, ignorar saberes de experiência feitos, como ponto de partida, como objeto de problematização, no processo educacional, provoca o erro epistemológico.

Charlot (2009), por sua vez, ao analisar o fenômeno da evasão escolar, destaca que há um exagero na ênfase dada ao campo da didática, geralmente desvinculada do campo sociológico. Para este autor, referindo-se à didática, "[...] ela supõe já dado o eu epistêmico, ou seja, a razão humana, um espírito querendo aprender, um aluno intelectualmente mobilizado" (p. 21). Ainda, na análise de Charlot, somente ocorre aprendizagem quando alguém se mobiliza numa atividade intelectual. E "só se mobiliza numa atividade intelectual 
quem acha um sentido nela" (p. 29). Para este autor (CHARLOT, 2009), a didática, de forma majoritária, ignora a primeira, focalizando a segunda parte da pergunta: Quando alguém quer estudar, qual o melhor método para ensiná-lo?

É uma lacuna, já anteriormente referida, que ignora os que não querem estudar, a maioria. Lacuna associada a não problematização da organização do espaço-tempo da escola, do currículo. Um espaço-tempo caracterizado pela fragmentação disciplinar, pela realização de muitas tarefas sem sentido, comprometendo a compreensão de temas, de problemas contemporâneos marcados pela complexidade não abarcável pelo viés unicamente disciplinar.

Há indicativos, sinalizações, nesta pesquisa, de que, para superar a evasão, é fundamental problematizar e superar a lógica de organização do espaço-tempo da escola, inspirada na linha de montagem das fábricas do início do século XX. Um dos estudantes, cujo nome foi resgatado do arquivo morto, aponta, mesmo sem uma teorização acabada, para uma nova escola. Sinaliza para a construção de um currículo por todos os envolvidos: estudantes, professores, diretora, toda equipe da escola. Nesta escola, cada um poderá falar, cada um deverá ser livre para se expressar, independente de que papel exerce. Todos juntos "pensando, debatendo, discutindo". Possivelmente nem conheça obras, ou o conjunto da obra do educador Paulo Freire. Porém, sua experiência de estudante, seus abandonos, levaram-no, sem refinamentos teóricos, mas carregados de experiência de vida, a formular uma concepção curricular muito próxima da práxis educacional freireana. Em síntese, está em aberto, permanece o desafio de conceber e executar configurações curriculares pautadas por outras lógicas de organização espaço-temporal, distintas daquela em que os sujeitos da presente pesquisa evadiram ou foram evadidos.

\section{Referências}

ANGELUCCI, C. B. et al. O estado da arte da pesquisa sobre o fracasso escolar (1991-2002): um estudo introdutório. Educação e Pesquisa, São Paulo, v. 30 , n. 1, p. 51-72, jan./abr. 2004.

AULER, D. Articulação entre pressupostos do educador Paulo Freire e do movimento CTS: novos caminhos para a educação em ciências. Contexto \& Educação, ljuí, v. 1, n. 77, p. 167-188, 2007.

BARDIN, L. Análise de Conteúdo. Lisboa: Edições 70, 1977.

BRAVERMAN, H. Trabalho e capital monopolista: a degradação do trabalho no século XX. Rio de Janeiro: LTC, 1987. 379p.

CHARLOT, B. A construção social da noção de fracasso escolar: do objeto sociomidiático ao objeto de pesquisa. In: ARROYO, M. G.; ABRAMOWICZ, A. A Reconfiguração da Escola: entre a negação e a afirmação de direitos. Campinas: Papirus, 2009. 
DEL PINO, M.B. A exclusão escolar na rede pública municipal de ensino: A história continua no século XXI. FAPERGS. Disponível em: <http:// www.anped.org.br/reunioes/30ra/trabalhos/GT13-3803-int.pgf>. Acesso em: 21 out. 2009.

FARIA FILHO, L. M. de; VIDAL, D. G. Os tempos e os espaços escolares no processo de institucionalização da escola primária no Brasil. Revista Brasileira de Educação, São Paulo, n. 14, maio/jun./jul./ago., 2000.

FREIRE, P. Pedagogia do oprimido. 17. ed. Rio de Janeiro: Paz e Terra, 1987. 1985.

Por uma pedagogia da pergunta. 3. ed. Rio de Janeiro: Paz e Terra,

Pedagogia da esperança: um reencontro com a pedagogia do oprimido. Rio de Janeiro: Paz e Terra, 1992.

FREIRE, P.; SHOR, I. Medo e ousadia: cotidiano do professor. 10. ed. Rio de Janeiro: Paz e Terra, 1986.

MIDEPLAN. MINISTÉRIO DE PLANEJAMENTO DO CHILE. Adolescentes y jóvenes que abandonan sus estudios antes de finalizar la enseñanza media: principales tendências. Disponível em: <http://www.oei.es/quipu/chile/ desercionescolar.pdf>. Acesso em: 25 jul. 2008.

MOVIMENTO DOS TRABALHADORES RURAIS SEM-TERRA. Escola itinerante em acampamentos do MST. Estudos Avançados, São Paulo, v. 15, n. 42, p. 235-240, 2001.

SACRISTÁN, J. G. O currículo: uma reflexão sobre a prática. 3. ed. Porto Alegre: Artmed, 2000.

SILVA, T. T. Documentos de identidade: uma introdução às teorias do currículo. 2. ed. Belo Horizonte: Autêntica, 2004.

TONUCCI, F. Frato: 40 anos com olhos de criança. Porto Alegre: Artmed, 2008.

TRIVIÑOS, A. N. S. Introdução à pesquisa em ciências sociais: a pesquisa qualitativa em educação. 1. ed. São Paulo: Atlas, 2008. 


\section{Apêndice 1 - Questionário}

1) Idade:

2) Sexo: ( ) F ( ) M

3) Você mora próximo da escola? Detalhe.

4) Turno que estudava quando parou: ( ) manhã ( ) tarde

5) Quanto tempo faz que você saiu da escola?

5) O que você faz atualmente?

6) Você possui dependentes? ( ) Não ( ) Sim Quantos?

7) Você repetiu de ano?

( )Não

( ) Sim ( ) Uma vez ( ) Duas vezes ( ) Três vezes ( ) Quatro vezes ( ) Cinco vezes

9) Por que você parou de estudar?

10) Você procurou voltar? O que aconteceu?

\section{Apêndice 2 - Entrevista semi-estruturada realizada com E8}

1) Na questão n. 9 do questionário: "Por que você parou de estudar?" você diz: "o que tinha fora da escola me chamava atenção ...ou devia ter alguma coisa lá dentro da escola que não me chamava atenção". Você poderia comentar um pouco mais sobre isso?

2) Você fez uma observação em que fala sobre ter "uma matéria que chamasse atenção do aluno, como falar do dia a dia, um assunto em que todos participem...", você poderia aprofundar um pouco mais, falar mais sobre isso?

3) Você poderia falar mais sobre o que você nomeia como $o x$ da evasão, 0 assunto que realmente envolve o aluno, que "pega"? Os alunos diferentes;.

4) E sobre "o aluno não ter interesse, não discute". Você poderia falar mais?

5) Para você, como a escola poderia "trazer o aluno para dentro dela", como você falou?

6) Qual a importância que você dá ou como você qualifica a importância de atividades que favoreçam o convívio entre os colegas como interséries? O que você sugere?

7) O que você modificaria na escola para que reduzisse a evasão escolar? 


\section{Notas}

${ }^{1}$ No âmbito da arquivologia, questiona-se a designação "arquivo morto". Contudo, aqui, manteve-se tal nomenclatura considerando ter sido apontado como sendo o local em que a pesquisadora deveria localizar os estudantes evadidos.

2 O Fordismo é um modelo de produção em massa idealizado pelo empresário estadunidense Henry Ford (1863-1947), fundador da Ford Motor Company. Esse modelo revolucionou a indústria automobilística a partir de janeiro de 1914, quando introduziu a primeira linha de montagem automatizada. Nessa, os veículos eram montados em esteiras rolantes que movimentavam-se enquanto o operário ficava praticamente parado, realizando uma pequena etapa da produção. Dessa forma, não era necessária quase nenhuma qualificação dos trabalhadores.

3 Taylorismo ou administração científica é o modelo de administração desenvolvido pelo engenheiro estadunidense Frederick Taylor (1856-1915). Caracteriza-se pela ênfase nas tarefas, objetivando o aumento da eficiência. Consiste na divisão das funções dos trabalhadores, os quais, "liberados" de qualquer iniciativa, cumprem mecanicamente as tarefas.

${ }^{4}$ Os sujeitos que responderam o questionário e que foram selecionados para a entrevista foram identificados como E1, E2, E3, E4, E5, E6, E7 e E8.

${ }^{5}$ Escola organizada "a partir da elaboração de uma proposta pedagógica para dar atendimento às crianças, aos adolescentes e aos jovens dos acampamentos dos Sem-Terra" (Movimento dos Trabalhadores Rurais Sem-Terra, 2010).

\section{Correspondência}

Luciana Vigil Ferrão - Universidade Federal de Santa Maria, Centro de Educação, Av. Roraima, 1000, CEP: 97105-900, Santa Maria, Rio Grande do Sul, Brasil.

E-mail: lukiana.ferrao@gmail.com - auler.ufsm@gmail.com

Recebido em 15 de junho de 2011

Aprovado em 11 de novembro de 2011 